\title{
A Motivação e a Inversão da Pirâmide de Maslow
}

\author{
Ivaneide de Farias Dantas ${ }^{1}$
}

\begin{abstract}
Resumo
$\mathrm{O}$ artigo aqui apresentado tem como objetivo analisar e compreender os fatores motivacionais que impulsionam profissionais de educação do ensino básico a buscarem a melhoria do perfil profissional a partir de sua participação em cursos de especialização lato sensu na área de educação. Os resultados permitem identificar e compreender os principais fatores que motivam os professores na busca de ampliação do seu conhecimento, que, com base nos principais teóricos da motivação, e, especificamente em Maslow, podemos perceber como se comporta a pirâmide de necessidades diante das respostas dos professores, caracterizando como principais fatores motivacionais a profissionalidade e a prática docente.
\end{abstract}

Palavras-chave: Formação Continuada, Motivação e Prática Docente.

\section{The Motivation and Inversion of Maslow Pyramid}

\begin{abstract}
The article presented here aims to analyze and understand the motivational factors that motivate primary education professionals to seek the improvement of their professional profile based on their participation in lato sensu specialization courses in the area of education. The results allow us to identify and understand the main factors that motivate teachers in the search for the expansion of their knowledge, which, based on the main theorists of motivation, and specifically in Maslow, we can understand how the pyramid of needs behaves in front of the answers of the professors, characterizing as main motivational factors professionalism and teaching practice.
\end{abstract}

Keywords: Continuing Education, Motivation and Teaching Practice.

\footnotetext{
1 Analista Organizacional, formada em Licenciatura Plena em Ciências e Bel. em Psicologia, especialista em Administração Pública pela FGV-Fundação Getúlio Vargas e em Administração de RH pela Universidade Católica de Pernambuco. Mestre em Administração Pública pela FGV - Fundação Getúlio Vargas e Doutoranda em Administração pela UNAM-Universidad Nacional de Misiones na Argentina. Atualmente é Secretária Municipal de Educação e Professora da UNINASSAU.
} 


\section{A Motivação e a inversão da pirâmide de Maslow}

\section{Introdução}

Existem muitas teorias sobre motivação que dão base aos estudos do comportamento humano nas organizações. Esses estudos tiveram maior relevância nos anos 1920 com a escola comportamental, tendo como ícone a pesquisa de Elton Mayo em 1924 na Western Electric Company. A partir disso, muitos cientistas cuidaram de pesquisar sobre o comportamento das pessoas em situação de trabalho contemplando quase sempre o tema motivação, considerando sua relevância e a necessidade das organizações para que as pessoas ampliassem sua disposição para realizarem suas tarefas.

No presente artigo apresentaremos um estudo sobre motivação de professores onde existem indicativos muito claros de que essa categoria de trabalhadores tem motivos bem diferentes do que outros profissionais de outras áreas.

A preocupação inicial na pesquisa foi a descoberta do que motiva esses profissionais a buscarem cursos de especialização e como isso pode contribuir para a melhoria dos indicadores educacionais, tendo em vista o baixo índice de desempenho de nossos estudantes no Brasil, notadamente em escolas públicas.

No Brasil, aproximadamente 56,5 milhões de pessoas frequentam escola ou creche. Do total de estudantes, 73,5\% (41,6 milhões de estudantes) frequentavam escola pública, enquanto $26,5 \%$, a rede privada.Trata-se de um contingente mais de $27 \%$ de nossa população considerando que a população no Brasil é de 207,7 milhões de habitantes. Portanto, estudos como esse é de grande valia, principalmente para políticas de formação desses professores.

Compreendemos que para contribuir com a melhoria dos indicadores atuais, a formação continuada dos professores pode ser uma alternativa importante, e que deve ser prioridade, para reverter os indicadores de desempenho escolar e com isso contribuir para a melhoria da qualidade da educação em nosso país. Conforme afirma Almeida (2005, p. 3), “[...] as questões relativas à atuação e à formação docente estão no centro de amplas discussões, ocorridas em fóruns que extrapolam os espaços dos especialistas ou dos gestores dos sistemas de ensino". 
O entendimento de formação continuada ou formação contínua para o presente artigo refere-se a um processo dinâmico, como explica Alarcão (1998, p. 100): "processo dinâmico por meio do qual, ao longo do tempo, um profissional vai adequando sua formação às exigências de sua actividade profissional". Essa adequação se dá a partir da participação desse profissional em cursos, capacitações, seminários e outros, ao longo de sua vida docente, num contínuo incremento de novos saberes.

Nesse contexto educacional onde verificamos que os indicadores mostram deficiências em nosso ensino e, tendo em vista serem os professores profissionais imprescindíveis para a construção do conhecimento de crianças e adolescentes que irão conduzir os rumos de nosso estado e do país, apresentamos a seguinte questão: quais os fatores motivacionais que mobilizam professores do ensino básico a participarem de cursos de especialização na área de educação?

A partir dessa questão, realizamos uma pesquisa com 122 alunos, pedagogos ou com licenciaturas diversas, de nove cursos de especialização oferecidos pela Faculdade Frassinetti do Recife - FAFIRE, Estado de Pernambuco, no ano de 2012, com o objetivo de delimitar os fatores motivacionais que levam os professores a buscarem qualificar cada vez mais seu perfil profissional.

\section{A Formação do Professor do Ensino Básico}

A formação inicial do professor do ensino básico, aqui compreendida como sendo a graduação em Licenciatura ou Pedagogia, ocorre, muitas vezes, em instituições sem as principais condições de estrutura e de professores qualificados para dar conta da responsabilidade social desses novos profissionais. As instituições de ensino superior em Licenciatura ou Pedagogia do estado de Pernambuco, especificamente no município do Recife, em sua maioria particular, possuem uma baixa avaliação pelos órgãos avaliadores oficiais do MEC, primam pela permanência do aluno de qualquer forma fazendo com que, muitas vezes, este profissional, apesar de formado, possua baixa qualificação, principalmente em relação à disciplina de atuação (conteúdos específicos).

Conforme assegura Guimarães (2005, p. 33), “a formação inicial é um processo fundamental na construção da identidade profissional do professor", por isso a importância do Estado em investir e exigir que os cursos superiores sejam oferecidos com qualidade de modo a atenderem o papel de formar profissionais qualificados para o mercado de trabalho. 
Segundo Scheibe (2010, p. 984), a maioria dos professores se submete a uma formação inicial precária e isso contribui para a má formação desse profissional.

“[...] o setor privado responde por cerca de $74 \%$ das matrículas em cursos de graduação presenciais no Brasil, a maior parte em instituições não universitárias, sobretudo em cursos noturnos. Tais instituições apresentam em geral, situação precária para a oferta dos cursos. Devido ao menor custo de oferta, as licenciaturas são, historicamente, privilegiadas por essas instituições. A maior parte dos professores no Brasil, portanto, é formada em instituições não universitárias e me cursos ofertados no período noturno".

O processo de formação do profissional da educação, especialmente os professores, não se limita apenas à graduação em licenciatura ou pedagogia, trata-se de um processo mais amplo e contínuo com a finalidade de dar sustentação às mudanças e às necessidades da sociedade, como por exemplo a expansão da informatização no meio acadêmico, pois, conforme Ludke e Boing (2004, p. 1170) “[...] a informática educativa está se colocando cada vez mais como um apêndice ao trabalho dos professores. Competências que seriam desejáveis que todo professor dominasse".

Considerando as deficiências na formação do docente, em sua maioria oriundos de escolas públicas e graduados em instituições de qualidade duvidosa, o professor sente a necessidade de continuar seus estudos numa tentativa de minimizar as deficiências e as lacunas causadas pelo seu processo de aprendizado. Porém, deve se dar conta de qual a formação que é necessária para a melhoria da sua prática ou está a serviço de regulações e desempenhos que modelam os profissionais numa expectativa de massificar a formatação das aulas e se obter os melhores resultados sem considerar nenhum grau de criticidade.

Para Fonseca (2004), os cursos de especialização têm por finalidade a qualificação para a docência no ensino fundamental e médio, atualização, preparação para o mestrado, formação continuada, especialização profissional e preparação para o magistério superior.

\section{Fatores Motivacionais e a Necessidade de Aperfeiçoamento}

Muitos teóricos consideram que o termo motivação tem relação estreita com as necessidades do ser humano. Para Maslow (1970), as necessidades são consideradas o princípio da teoria da motivação e denominadas de motivadores psicológicos. $\mathrm{O}$ autor nos apresenta cinco necessidades, acrescentando ainda uma última, a qual denominou de "estética". As necessidades básicas e hierarquizadas, apresentadas por Maslow, conforme figura 1, são: fisiológica, de segurança, de amor, de estima e de autorrealização. Quando uma 
necessidade está satisfeita surge outra que mobiliza o ser humano. Assim, Mosquera (1982, p. 25) apresenta a ideia de Maslow:

“[...] a satisfação de uma necessidade e sua conseqüente remoção do centro do palco provocam não um estado de repouso ou de apatia estóica, mas antes, o aparecimento, na consciência, de outra necessidade mais alta; a carência e o desejo continuam, mas em nível superior".

Figura 1 Pirâmide de Maslow

\section{Pirâmide de Maslow}

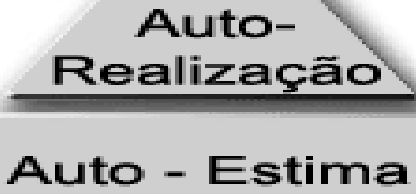

Necessidades Fisiológicas Básicas

Fonte: site.suamente.com.br/a-piramide-de-maslow/

De todas as necessidades descritas, interessa-nos para o presente estudo, principalmente, a necessidade de autorrealização, muito embora isso não queira dizer que as outras necessidades estão totalmente satisfeitas. Quer dizer apenas que existe o interesse do indivíduo em se atualizar, tanto no plano emocional, através de valores da verdade, bondade, justiça, autossuficiência e outros, quanto na melhoria do conhecimento que favorece o fortalecimento dos valores e de sua autonomia (emancipação). Essa é outra ideia de Maslow que se ajusta no contexto e que Mosquera (1982, p. 33) nos apresenta: “Auto-atualização é a tendência de realizar o potencial. Essa tendência pode ser expressa como o desejo de a pessoa tornar-se sempre mais o que é e vir a ser tudo o que pode ser".

De forma resumida, de acordo com os autores citados, podemos inferir que a motivação, basicamente, tem relação com a ação, pois por trás de toda ação existe uma energia psíquica e biológica que impulsiona o indivíduo a agir em direção ou rejeição ao objeto. 
Essa energia psíquica disponível é usada para dois objetivos: para a realização do trabalho necessário à manutenção da vida e à propagação da espécie considerando como funções inatas e instintivas. A energia que exceder a necessária a estes instintos pode ser empregada em outras atividades tais como culturais e espirituais que constituem um propósito mais elevado.

O nível de complexidade de comportamentos que o ser humano apresenta ao lidar com os fenômenos do seu dia a dia é de fato impressionante pela pluralidade de reações e de difícil controle para especialistas na área de psicologia. Para Murray (1986, p. 11), "os usos que uma pessoa der às suas capacidades humanas dependem de suas motivação - seus desejos, anelos, carências, necessidades, ambições, apetites, amores, ódios e medos".

Para Murray (1986, p. 20), “um motivo é um fator interno que dá início, dirige e integra o comportamento de uma pessoa”. Nessa perspectiva percebe-se que é difícil afirmar que um indivíduo possa motivar outro, de forma consciente, impelindo-o a comportamentos pré-planejados.

A motivação é portanto algo particular do indivíduo que depende da situação no momento em que ela ocorre e da forma como foram apreendidas as experiências individuais e sua forma de perceber o mundo e a si próprio.

Murray (1986 p. 22) ainda leva em consideração que

\footnotetext{
"Uma pessoa é motivada, em qualquer momento, por uma variedade de fatores internos e externos. A força de cada motivo e o padrão de motivos influem na maneira como vemos o mundo, nas coisas em que pensamos e nas ações em que nos empenhamos".
}

Conclui ainda Murray (1986, p. 39) que a motivação determina o comportamento, seja ele voltado para a "aprendizagem, desempenho, percepção, atenção, recordação, esquecimento, pensamentos, criativida e sentimento".

\section{Organização e a Motivação para a Ampliação do Conhecimento}

Uma teoria bastante abordada pelos estudiosos do mundo organizacional é a teoria de Maslow, já referenciada, e que coloca a satisfação de necessidades, de forma hierarquizada, como sendo a base da motivação, muito embora Robbins $(1999$, p. 110) alerta para o fato de que pesquisas realizadas não validaram a teoria, visto que "pouca sustentação foi descoberta para a previsão de que as estruturas de necessidades estão organizadas nas dimensões propostas por Maslow". 
A motivação humana dentro de uma dimensão histórica durante muito tempo foi estudada sob o prisma do impulso ou do instinto. As teorias mais contemporâneas se baseiam na percepção social e nas perspectivas cognitivas mudando com isso o seu foco para o comportamento dos seres humanos diante de fenômenos sociais.

É importante aprofundar a análise das teorias da motivação e estabelecermos de que forma essas teorias irão contribuir com o estudo da motivação do professor para fazer um esforço adicional e participar de cursos de pós-graduação.

Os estudos realizados por Guimarães e Boruchovitch (2004) apontam para uma nova teoria desenvolvida pelos pesquisadores Deci e Ryan. Trata-se da Teoria da Autodeterminação. Conforme Deci e Ryan (2000 apud GUIMARÃES; BORUCHOVITCH, 2004, p. 144), “a base inicial para a Teoria da Autodeterminação é a concepção do ser humano como organismo ativo, dirigido para o crescimento, desenvolvimento integrado do sentido do self e para integração com as estruturas sociais". Portanto, existe a necessidade das pessoas se sentirem competentes e autodeterminadas diferentemente de outras teorias que se baseiam em necessidades meramente fisiológicas.

O estudo da motivação é bastante importante para entendermos a necessidade de conhecermos e avaliarmos o que motiva as pessoas, e em nosso caso, o que motiva o professor para a busca de melhoria em sua prática educativa.

Os fatores motivacionais representam as necessidades a serem eliminadas para que o professor exerça a docência em sua plenitude. Esses fatores devem ser do conhecimento do gestor da organização educacional, pois, a partir dessa informação, é possível a implementação de políticas públicas voltadas para a capacitação efetiva do professor de modo a atendê-lo em suas dificuldades e, consequentemente, contribuir para a melhoria do processo de ensino-aprendizagem.

\section{Análise dos Fatores Motivacionais}

A partir da análise do instrumento de coleta de dados, que solicita ao respondente escolher a resposta mais adequada sobre os motivos que o levaram a fazer o curso de especialização, identificamos os itens que formam as categorias e se consolidam como sendo os fatores motivacionais que estimulam os professores a participarem de cursos de especialização. Os itens estão estruturados conforme o modelo de Likert, perfazendo um total 
de 16 itens com as seguintes possibilidades de respostas: Concordo, Concordo Parcialmente, Nem Concordo e Nem discordo, Discordo Parcialmente e Discordo.

Os 16 itens que os respondentes tiveram que avaliar e responder foram escolhidos de modo a obtermos uma visão geral em relação ao contexto vivido pelos indivíduos. Com isso optamos por disponibilizar nos questionários os seguintes itens: a) Atender solicitação da família; b) Prazer e satisfação pessoal; c) Melhorar minha imagem diante da minha família e de meus colegas; d) Ampliar meu nível de escolaridade para seguir carreira acadêmica (Mestrado e Doutorado); e) Ampliar meus conhecimentos; f) Atualizar o conhecimento; g) Qualificar minha prática pedagógica; h) Facilitar o processo de aprendizagem do aluno; i) Melhorar o meu currículo e com isso minha competitividade no mercado de trabalho; j) Conhecer outros profissionais-formação de rede; k) Melhorar minha competitividade em concursos públicos; 1) Solucionar problemas específicos na prática profissional; m) Melhorar minha qualificação para exercer cargo de gestão; n) Melhorar meu salário; o) Complementar lacuna de conhecimentos deixada pela graduação; p) Aproveitar o incentivo oferecido pela instituição em que trabalho (pagamento das mensalidades/liberação de carga horária/outro).

Dentre os itens apresentados foi possível categorizá-los para facilitar o nível de entendimento a partir das categorias denominadas: Pessoal, Profissionalidade, conforme conceitua Ramos (2010) e Prática Docente, Empregabilidade, Salarial e Complemento da Formação Inicial.

Dentro de uma visão mais geral, e numa tentativa de analisarmos os dados em conjunto e com uma maior clareza, podemos apresentar esses resultados referentes aos fatores motivacionais, conforme a tabela 1 .

Tabela 1 - Fatores Motivacionais

\begin{tabular}{|c|c|c|c|c|c|c|}
\hline $\begin{array}{c}\text { Fatores } \\
\text { Motivacionais }\end{array}$ & Concordo & $\begin{array}{c}\text { Concordo } \\
\text { Parcialmente }\end{array}$ & $\begin{array}{c}\text { Nem conc. e } \\
\text { nem disc. }\end{array}$ & $\begin{array}{c}\text { Disc. } \\
\text { Parcialmente }\end{array}$ & Discordo & $\begin{array}{c}\text { Não } \\
\text { Respondeu }\end{array}$ \\
\hline $\begin{array}{c}\text { Profissionalidade e } \\
\text { Prática Docente }\end{array}$ & $85 \%$ & $8 \%$ & $1 \%$ & $0 \%$ & $2 \%$ & $4 \%$ \\
\hline Empregabilidade & $73 \%$ & $9 \%$ & $5 \%$ & $1 \%$ & $8 \%$ & $4 \%$ \\
\hline Salarial & $70 \%$ & $12 \%$ & $5 \%$ & $0 \%$ & $7 \%$ & $5 \%$ \\
\hline $\begin{array}{c}\text { Complementar a } \\
\text { Formação Inicial }\end{array}$ & $61 \%$ & $17 \%$ & $6 \%$ & $2 \%$ & $10 \%$ & $4 \%$ \\
\hline Pessoal & $38 \%$ & $15 \%$ & $12 \%$ & $2 \%$ & $25 \%$ & $8 \%$ \\
\hline $\begin{array}{c}\text { Incentivo da } \\
\text { Empresa }\end{array}$ & $10 \%$ & $6 \%$ & $8 \%$ & $2 \%$ & $64 \%$ & $10 \%$ \\
\hline
\end{tabular}

Fonte: Elaboração própria 
Nessa perspectiva, ao apreciarmos os resultados dos fatores motivacionais em conjunto, podemos deduzir que, para nossa amostra, o fator Profissionalidade e Prática Docente constitui-se como o mais significativo em relação aos outros fatores. $85 \%$ dos respondentes concordam que o fator mobilizado para a busca da ampliação dos conhecimentos é a melhoria da profissionalidade e da sua prática em sala de aula.

Conforme a tabela 1, o resultado nos mostra que a motivação dos professores não se baseia em necessidades ditas fisiológicas, nos mostrando que em relação à hierarquia das necessidades de Maslow existe uma reversão no fenômeno apresentado. $\mathrm{O}$ fator motivacional que figura como mais importante tem relação com a autorrealização o que nos leva a crer que a teoria de Deci e Ryan talvez possibilite uma maior compreensão do estudo, considerando que essa teoria trata primordialmente da necessidade que o ser humano tem de se sentir competente e autodeterminado.

Apesar de termos a maioria dos respondentes exercendo alguma profissão, verificamos que $73 \%$ de sua motivação está voltada para a empregabilidade. Isso pode ser consequência de algumas variáveis, tais como: possibilidade de possuir um segundo vínculo empregatício, necessidade de ascensão profissional e ampliação acadêmica.

O fator motivacional relacionado ao salário também pode ser considerado previsível se compararmos ao perfil dos respondentes, especialmente a sua renda. Para ampliar seu salário é necessário melhorar seu currículo. Com isso, as consequências podem relacionar-se à ampliação de vantagem para um novo emprego, embora não seja o fator mais importante.

$\mathrm{O}$ que podemos perceber com maior intensidade nos resultados dessa pesquisa foi que os professores pesquisados têm em si a responsabilidade de estarem constantemente atualizando seus conhecimentos e que avaliam sua atuação em sala de aula, e ao verificarem suas deficiências se incomodam com sua atuação. Isso é importante, considerando a autoavaliação e a ação para a melhoria das dificuldades vividas em sala de aula.

\subsection{Análise das expectativas em relação às competências adquiridas}

Para a avaliação da questão cuja pergunta foi: Ao término desse curso de especialização você espera ter adquirido quais competências? tivemos 114 respondentes que forneceram 130 respostas para essa pergunta.

A Tabela 2, considerando a análise das frequências, vem a consolidar o que dissemos em relação aos fatores motivacionais, pois o interesse maior dos nossos docentes é com os 
resultados de sua prática o que demonstra uma significativa profissionalidade para a resolução de questões consideradas pelo profissional.

Tabela 2 - Competências

\begin{tabular}{|c|c|c|}
\hline FATORES & FREQUÊNCIA & PERCENTUAL \\
\hline Profissionalidade e Prática Docente & 94 & $72 \%$ \\
\hline Empregabilidade & 27 & $21 \%$ \\
\hline Pessoal & 5 & $4 \%$ \\
\hline Complemento Lacuna da Formação & 3 & $2 \%$ \\
\hline Salário & 1 & $1 \%$ \\
\hline
\end{tabular}

Fonte: Elaboração própria

O termo competência é aqui utilizado como sendo "um saber agir responsável e reconhecido, que implica mobilizar, integrar, transferir conhecimentos, recursos e habilidades, que agreguem valor econômico à organização e valor social ao indivíduo" (FLEURY; FLEURY, 2001, p. 188). Muitas respostas se apresentam como tratando de várias competências ao mesmo tempo. Todos os enunciados foram considerados para fins de tabulação.

Sobre o fator motivacional denominado de empregabilidade, verificamos que $21 \%$ dos respondentes querem ter melhores condições para enfrentar o mercado de trabalho, especialmente se esse relacionar-se com o ensino superior.

Com isso, podemos assumir que, com relação às competências que os alunos esperam adquirir com sua participação no curso, praticamente essas competências estão relacionadas com a profissionalidade e prática docente e empregabilidade, guardando, com esse resultado, uma estreita relação com os resultados relacionados aos fatores motivacionais que levam esses profissionais a participarem do curso.

Percebe-se também, muito claramente, que o item salário, que pode ser considerado como um item para a satisfação de necessidades básicas, ficou em última colocação, o que corrobora com a nossa tese de que, no caso de professores, a grande motivação refere-se a autorrealização.

\subsection{Análise das contribuições do curso para a celhoria da prática profissional}

Nossa última questão apresentada ao respondente foi: de que forma esse curso de especialização pode contribuir para a melhoria de sua prática profissional? Assim como a questão anterior, trata-se de uma pergunta aberta de difícil interpretação e com necessidade de também categorizarmos suas respostas. A ideia foi a de relacionar as respostas às categorias 
que os respondentes acreditam que dão sustentação à sua prática pedagógica, tais como: Conhecimento, Relacionamento interpessoal, Postura profissional, Resolução de problemas, Reflexão da prática, Segurança, Inovação, Qualificação curricular e Melhoria salarial. Os resultados estão expostos na Tabela 3.

Tabela 3 - Contribuições para a prática

\begin{tabular}{|c|c|c|}
\hline FATORES & FREQUÊNCIA & PERCENTUAL \\
\hline Conhecimento & 64 & $56 \%$ \\
\hline Segurança & 20 & $17 \%$ \\
\hline Reflexão da Prática & 9 & $8 \%$ \\
\hline Resolução de Problemas & 7 & $6 \%$ \\
\hline Relacionamento Interpessoal & 5 & $4 \%$ \\
\hline Qualificação Curricular & 5 & $4 \%$ \\
\hline Postura Profissional & 2 & $2 \%$ \\
\hline Inovação & 2 & $2 \%$ \\
\hline Melhoria Salarial & 1 & $1 \%$ \\
\hline
\end{tabular}

Fonte: Elaboração própria

De acordo com os dados apresentados, a busca pelo conhecimento é a grande contribuição que um curso de especialização pode oferecer para a prática docente, de acordo com a visão dos respondentes. Outros itens como segurança, reflexão da prática e resolução de problemas aparecem como contribuições que dão sustentação à prática docente. Os itens como relacionamento interpessoal, qualificação curricular, postura profissional, inovação e melhoria salarial aparecem de forma tímida. E novamente, confirma-se o pensamento de que o salário não é, definitivamente, o grande propósito do professor. Nessa tabela observamos claramente que os componentes que tem relação com a autorrealização são de fato os itens voltados as necessidades desses profissionais.

As expectativas desses alunos são muito grandes e as instituições formadoras tem um grande desafio a ser superado: atender essas expectativas. Além de tudo isso, o local de trabalho deve estar receptivo a esse professor que se reforma a cada aquisição de conhecimento, que tem motivação para ampliar sua carreira e melhorar sua prática. Apesar de sabermos que a motivação está dentro de cada um de nós, é importante que o contexto vivido dê subsídios para estimular esse profissional a buscar muito mais, como afirma Bergamini (1990, p. 112):

“Afirmar que o impulso motivacional nasce no interior de cada um não significa que sua manutenção dependa única e exclusivamente só dessas pessoas. De nada adianta essa sinergia individual se o ambiente organizacional não esteja facilitando o seu livre curso". 
Em outras palavras, a autora reforça a ideia de que o ambiente de trabalho deve apresentar as condições objetivas para que esse profissional possa efetivamente aplicar os conhecimentos em sala de aula, reconhecer sua nova performance e ter o reconhecimento dos alunos que existe uma melhoria na prática desse profissional, de modo que a relação ensino aprendizagem se estabeleça e reforce as competências dos alunos para que os índices educacionais melhorem e consigam acompanhar o desempenho esperado pelo poder público brasileiro e por parâmetros internacionais.

\section{Conclusão}

Os resultados referentes às respostas aos questionários evidenciaram que os fatores motivacionais voltados para a profissionalidade, conhecimento e prática docente, de fato, mobilizam esses profissionais para a busca de oportunidades e melhorias na vida profissional. O fator motivacional profissionalidade e prática docente teve resultado significativo para esses profissionais, pois buscam melhorar sua prática docente, afirmando que os fatores motivacionais que levam os professores a participarem dos cursos estão voltados para a prática pedagógica e ampliação do conhecimento.

Do ponto de vista dos teóricos que tratam do tema motivação, especialmente em relação a teoria de Maslow, encontramos uma hierarquia de necessidades desses profissionais onde a realização das necessidades básica não se apresenta como a mais importante, embora, em percentual tenha seu nível de importância. O que nos chama a atenção é a inversão da pirâmide de Maslow, quando a necessidade de autorrealização vem como primeira necessidade a ser satisfeita. Maslow, em seus escritos dimensiona a satisfação de necessidades básicas, ditas fisiológicas, como a primeira necessidade a se buscar satisfação. No caso dos professores, conforme estudo apresentado, trata-se de uma categoria que está voltada, inicialmente para seu preparo intelectual, apesar dos baixos salários. Talvez os estudos de Decy e Ryan possam contribuir melhor para explicar o fenômeno, tendo em vista que, nesse caso, a necessidade dos professores em se sentirem competentes e autodetermianados se apresenta como o fator motivacional principal para a busca de conhecimento como a realização de cursos de especialização.

Os resultados oriundos das questões abertas, de análise qualitativa, foram importantes para a consolidação desses fatores motivacionais e para estabelecermos relações com a prática dos profissionais. As contribuições para a prática do professor tiveram itens, após a 
categorização, voltados para os fatores motivacionais: Conhecimento, Segurança, Reflexão da Prática, Resolução de Problemas, Postura Profissional e Inovação, representando 91\% de respostas, sendo itens voltados para a profissionalidade e a prática docente do professor. As respostas referentes às competências requeridas pelos respondentes relacionam-se diretamente com os fatores motivacionais tendo a profissionalidade e prática docente também como um fator motivacional relevante.

Um fato curioso que podemos ressaltar é que, apesar da baixa remuneração dessa categoria de trabalhadores, esse profissional não considera como fator primordial a realização de um curso de especialização com o objetivo de melhorar seu salário. O fator mobilizador principal é a melhoria de sua ação docente com consequência, aquisição de conhecimento para contribuir com o aprendizado dos alunos.

Nesse contexto, outras questões podem ser levadas em conta para contribuir com a reflexão da nossa pesquisa, pois, apesar do empenho de nossos professores em se qualificarem, como as escolas tratam esse profissional melhor preparado? Será que os novos saberes estão tendo possibilidades de se manifestarem na prática docente? Será que os alunos conseguem sentir diferença nas aulas desse professor que está sendo capacitado? 


\section{Referências}

ALARCÃO, Isabel. Formação Continuada como Instrumento de Profissionalização Docente. In: VEIGA, Ilma Passos Alencastro (org.). Caminhos da Profissionalização do Magistério. Campinas, SP: Papirus, 1998. Coleção Magistério: Formação e Trabalho Pedagógico.

ALMEIDA, Maria Isabel de. Formação Continuada de Professores. In: Boletim 13. Formação Contínua de Professores. MEC. 2005. Disponível em: <http://www.tvbrasil.org.br/fotos/salto/series/150934FormacaoCProf.pdf>.

BERGAMINI, Cecília Whitaker. Motivação. 3. ed. São Paulo: Atlas, 1990.

BRASIL. Lei de Diretrizes e Bases da Educação Nacional no 9.394, de 20 de dezembro de 1996. Disponível em: <http://portal.mec.gov.br/arquivos/pdf/ldb.pdf>. Acesso em: 30 abr. 2010.

FLEURY, Maria Tereza Leme; FLEURY, Afonso. Construindo o Conceito de Competência. RAC, Curitiba, Edição Especial, 2001: 183-196.

FONSECA, Dirce Mendes. Contribuições ao Debate da Pós-graduação lato sensu. R.B.P.G. Brasília, v.1, n.2, p. 173 - 182. Nov. 2004.

GUIMARÃES, Sueli Édi Rufini; BORUCHOVITCH, Evely. O Estilo do Professor e a Motivação Intrínseca dos Estudantes: Uma Perspectiva da Teoria da Auto Determinação. Psicologia: Reflexão e Crítica, Londrina, 17(2), PP. 143-150, 2004.

INSTITUTO NACIONAL DE ESTUDOS E PESQUISAS EDUCACIONAIS ANÍSIO TEIXEIRA-INEP. Avaliação externa das instituições de ensino superior. Brasília, 2006a.

LUDKE, Menga; BOING, Luiz Alberto. Caminhos da Profissão e da Profissionalidade Docentes. Educação e Sociedade, Campinas, vol. 25, n. 89, p.1159-1180, Set/Dez, 2004.

MASLOW, A. H. Motivation and Personality. 2.ed. New York: Harper \& Row, 1970.

MOSQUERA, Juan José M. A Motivação Humana na Concepção de A. H. Maslow. In: PUENTE, Miguel de La (Org.). Tendências Contemporâneas em Psicologia da Motivação. São Paulo: Autores Associados: Cortez, 1982.

MURRAY, Edward J. Motivação e Emoção. 5. ed. Rio de Janeiro: Editora Guanabara Koogan S.A., 1986.

RAMOS, Kátia Maria da Cruz. Profissionalidade Docente Universitária: Um conceito em (RE) construção. Ensino Em - Revista, Uberlândia, v.17, n.2., p.561-578, jul./dez.2010.

ROBBINS, Stephen P. Comportamento Organizacional. 8. ed. Rio de Janeiro: LTC Livros Técnicos e Científicos Editora S.A., 1999.

RYAN, Richard M.; DECI, Edward L.. Self-Determination Theory: Basic Psychological Needs in Motivation, Development, and Wellness . Guilford Publications. Edição do Kindle, 2017. 